Claremont Colleges

Scholarship@ Claremont

CMC Senior Theses

CMC Student Scholarship

2016

\title{
A Re-Examination of Rating Shopping and Catering using Post-Crisis Data on CDOs
}

Robert H. Owlett

Claremont McKenna College

\section{Recommended Citation}

Owlett, Robert H., "A Re-Examination of Rating Shopping and Catering using Post-Crisis Data on CDOs" (2016). CMC Senior Theses. Paper 1408.

http://scholarship.claremont.edu/cmc_theses/1408

This Open Access Senior Thesis is brought to you by Scholarship@Claremont. It has been accepted for inclusion in this collection by an authorized administrator. For more information, please contact scholarship@cuc.claremont.edu. 
Claremont McKenna College

A Re-Examination of Rating Shopping and Catering using Post-Crisis Data on CDOs

submitted to

Professor Fan Yu

by

Robert H. Owlett

for

Senior Thesis

Spring 2016

April 25 ${ }^{\text {th }}, 2016$ 



\section{Acknowledgments}

I would like to thank Professor Fan Yu for his support and knowledge throughout the creation of this thesis. His guidance was instrumental in transforming my initial desire to write a thesis on structured products into a focus, final product on CDOs. I would also like to thank the CMC faculty, especially the professors that teach in the Robert Day Scholars program. I would like to thank the Financial Economics Institute and Terri Van Eaton for providing me access to the research institute and Bloomberg Terminals. I would like to thank Noah Jones and Ryan Beauchamp for their mentorship during my internship with Wells Fargo Securities. Finally, I would like to thank my parents, Tom and Sue, for their unwavering commitment to my education. 


\begin{abstract}
I re-examine "rating shopping" and "rating catering" in the market for AAA rated collateralized debt obligations (CDOs) by replicating the study of Griffin and Tang (2013) using post-crisis data. I find a sharp increase in the amount of CDOs that received a single rating, suggesting that $\mathrm{CDO}$ underwriters were more cautious about formally soliciting multiple ratings. However, I also find a decrease in AAA rating disagreements between S\&P and Moody's, implying that issuers shopped their CDOs through informal conversations with agencies. Finally, I find investors correctly accepted tighter credit spreads for dual-rated CDOs because dual-rated CDOs experienced fewer rating downgrades than single rated deals. These results differ from the pre-crisis findings of Griffin and Tang (2013) and are consistent with the existence of rating shopping and disappearance of rating catering during the post-crisis period.
\end{abstract}




\section{Table of Contents}

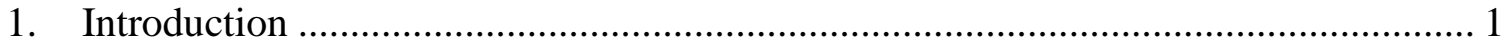

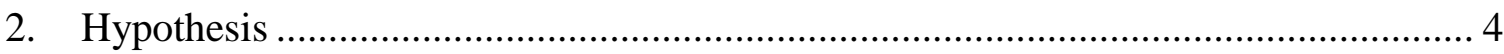

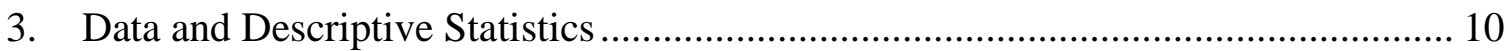

4. Does CDO Issuance by Rater Suggest Shopping or Catering? .............................. 12

5. Do Investors Perceive Additional Information from Multiple Ratings? .................. 17

6. Does CDO Performance Suggest Shopping or Catering? ..................................... 19

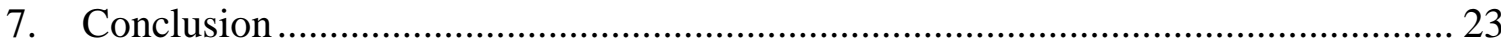

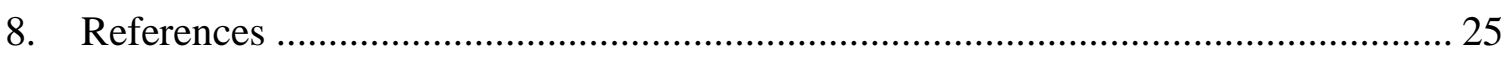

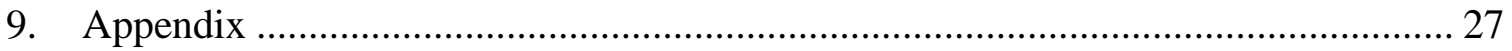




\section{Introduction}

Investor reliance on the two major credit rating agencies to accurately and unbiasedly rate collateralized debt obligations (CDOs) has been targeted by the DoddFrank Act as a main factor leading to the financial crisis of 2008. In the years leading up to the burst of the housing bubble and financial collapse, the major credit rating agencies were assigning AAA ratings to large portions of $\mathrm{CDO}$ capital that subsequently experienced major downgrades and events of default. These downgrades motivate the issue of whether the major credit rating agencies fully understood the risks associated with the complex, structure products or whether their ratings were systematically biased upward. The fact that $\mathrm{CDO}$ ratings did not fully reflect their risk before the financial crisis raises the question of whether the products' ratings can be trusted in the future. Thus, this paper attempts to replicate the study by Griffin and Tang (2013) on pre-crisis rating shopping and catering to uncover investor perception and rating agency behavior toward AAA rated CDOs after the financial crisis in the post Dodd-Frank era.

Overall, the literature contains two prominent theories attempting to explain the inaccuracy of CDO ratings which eventually led to the financial crisis. The first, rating shopping, involves $\mathrm{CDO}$ issuers soliciting ratings from multiple rating agencies with the intention of only disclosing the most favorable ones. Before Dodd-Frank, CDO issuers could choose to hide unfavorable ratings by paying a small contract breaking fee (Griffin and Tang (2013), Spatt and Sangiorgi (2011)). The theory relies on the assumption that the agencies' different rating methodologies result in a distribution of ratings. Thus, rating shopping is not related to inherently incorrect ratings standards or systematic biases on the part of rating agencies such as S\&P and Moody's. Rather, rating agencies' 
best efforts to assess true credit quality become biased by issuers' selective disclosure of favorable ratings.

The Dodd-Frank Act contains a provision attempting to decrease the opportunity for CDO issuers to hide unfavorable ratings by eliminating the option to break the ratings contract (SEC (2014)). As a result, Dodd-Frank requires CDO issuers to report the results of ratings formally solicited to rating agencies. Ideally, this provision should result in less rampant rating shopping compared to the pre-crisis era because all findings from rating solicitations are now disclosed to investors. The number of formal ratings solicitations now reflects the number of ratings completed and disclosed. In reality, however, preliminary discussions about credit quality occur between investment banks and ratings agencies. Through these informal talks, the CDO underwriters obtain an idea of the probable rating of their $\mathrm{CDO}$ and rating shop using this information.

The other predominant theory, rating catering, builds on rating shopping yet directly implicates wrongdoing on the part of the rating agencies. It hypothesizes that because CDO issuers are shopping for the most favorable rating, credit agencies do not adhere to their strict rating standards due to competitive pressures. Regardless of reputational concern, rating agencies inflate credit ratings to gain revenue and market share. Because each agency is stretching their standards to match their possible competitors, the result is inflated ratings by all agencies. In a sense, rating catering implies a "race to the bottom" where CDOs receive ever more favorable ratings while rating agencies compete for market share (Golan, Parlour, and Rajan (2011)).

Griffin and Tang (2013) provide the basis for my study and contribute the primary literature to rating shopping and catering of CDOs. Their study contrasts differences in 
credit spreads and ratings downgrades between single and multiple AAA rated CDOs. From 1997 to 2007 , they find that $96.3 \%$ of capital rated by both S\&P and Moody's received identical AAA tranche ratings. At CDO issuance, investors perceived dual-rated securities to be safer due to the additional informational content and required higher yield spreads for single rated securities. However, dual-rated CDOs experienced more frequent and severe downgrades during the financial crisis, suggesting single rated deals were initially rated with more accuracy. Thus, Griffin and Tang (2013) find that in cases where CDOs were rated by multiple rating agencies, S\&P and Moody's extended additional AAA portions to cater their standards to match the rating of their competitor. Also, without the pressure to match a more favorable rating by the other agency, solo rated deals adhered to the model output and more accurately reflected the riskiness of the capital.

I contribute to the literature by replicating the study by Griffin and Tang (2013) by using data on CDOs originated after the financial crisis. I focus on competitive pressure as a direct and exogenous variable by examining the credit spread and average downgrade between single and multiple rated CDOs. I find that $59 \%$ of AAA capital rated by either S\&P or Moody's received a rating from the other agency. Of that dualrated capital, 96.8\% received matching AAA ratings from the two agencies. Investors perceived dual-rated capital to be safer than single rated due to the additional information, charging a 4 basis point spread. In addition, capital exclusively rated by S\&P was 1.8 times more likely to experience rating downgrades than dual-rated capital while Moody's rated capital was 3.9 times more likely than dual-rated capital. Unlike the findings of Griffin and Tang, dual-rated CDOs exhibited superior credit performance, 
suggesting dual-rated CDOs have additional information. Thus, investors correctly accepted tighter credit spreads for dual-rated CDOs after the crisis. These findings support the conclusion that rating catering is not a prevalent force in the post-crisis CDO market. However, despite consideration in the Dodd-Frank Act, rating shopping by CDO issuers appears to persist after the financial crisis.

\section{Hypothesis}

A CDO is a structured financial product composed of the securitization of a bundle of loans or mortgages in a special purpose vehicle. The bundled collection of loans is divided into tranches that dictate the priority of repayment for all of the tranche's principal and interest. As a result, the tranches act as a mechanism to create bond classes with varying risk levels and thus varying rates of return. Overall, a CDO transforms a group of loans with a static risk and return payoff into a credit instrument with various levels of risk for potential investors. As a result, relatively safe investors such as pension funds and relatively risky investors such as hedge funds can both seek CDO tranches with the risk and return levels appropriate for their investment strategies.

Once a CDO is formed by an underwriter, typically an investment bank, rating agencies model the loss correlation of the CDO's capital and its likely future default rates. Each credit rating agency is required to publish their rating criteria for modeling correlation and potential defaults (SEC (2014)). S\&P and Moody's have rating approaches that slightly differ, occasionally leading to capital with different ratings from the agencies. Griffin and Tang (2013) find that model-implied differences in AAA tranche size were $10.5 \%$ on average between S\&P and Moody's. However, the two 
agencies agreed on initial AAA tranche size in $96.3 \%$ of cases from 1997 to 2007. The authors suggest that the less favorable rating agency responded by assigning AAA capital beyond their rating model to compete with the other agency's more favorable initial rating. Thus, the positive AAA size adjustment by the less favorable rater is a direct response to competitive pressure and indicates rating catering. I do not replicate this portion of the findings by Griffin and Tang (2013) because the data is not readily available. The authors completed this study by obtaining the actual credit risk model outputs for 730 CDOs directly from S\&P and Moody's. However, I conduct my analysis with only the data available on Bloomberg, which includes tranche rating history and credit spreads.

Throughout the rating process, the $\mathrm{CDO}$ issuers remain in contact with the rating agencies. During this period, the underwriters may selectively disclose information about the preliminary rating findings of other credit rating agencies in an attempt to pressure the rating agency into a more favorable rating. Once the $\mathrm{CDO}$ is rated, it can be priced by the underwriter and sold into the market to investors. Due to the complexity of the product, the credit rating is heavily relied on as an assessment of the CDO's risk and the eventual price. As a result, the information produced by credit rating agencies is very important in shaping the decisions and potentially protecting a large number of investors including pensions, endowments, and foundations.

The empirical literature contains numerous studies criticizing the major credit rating agencies for their actions during the bull market conditions from 2002 to 2007. Specifically, the literature on the systematic upward bias of asset backed securities and CDOs is quite immense. Griffin and Tang (2012) find that a top credit rating agency 
frequently made upward adjustments to the size of the AAA tranche beyond the output from the rating model. In addition, CDOs with smaller AAA tranches received larger adjustments that subsequently performed worse during the crisis. Next, Griffin and Tang (2011) show that CDO surveillance reports shortly after issuance are a more accurate indicator of collateral quality than initial issuance reports. This suggests that rating agencies use more aggressive assumptions to rate CDOs in issuance models than ongoing surveillance reports. He, Qian, and Strahan (2011) contribute to the literature on systematic inflation of ratings by finding that rating agencies grant more generous AAA tranche sizes to issuers that represent a significant source of revenue sources. Finally, a number of studies show the decline in the rating standards of subprime mortgage-backed securities that led to more favorable ratings from 2005 to 2007 (Ashcraft, GoldsmithPinkham, and Vickery 2010). Overall, due to intentional, systematic inflation of ratings, the literature suggests that rating agencies heavily biased ratings and misguided investor expectations of risk before the crisis.

In addition, the literature does not find that reputational concern from the major credit rating agencies is enough of an incentive to produce accurate, unbiased ratings. Bolton, Freixas, and Shapiro (2012) create a model to explain how credit rating agencies are prone to inflate ratings in cases where the reputational risk of detection is low. For example, CDOs are a likely candidate for inflation because the securities have a larger fraction of investors that solely rely on the rating agency's analysis. The Dodd-Frank addresses independent analysis of securities, however the cost and effort required to conduct the analysis discourages this behavior. Furthermore, Xia (2013) adds to the literature of reputational concern by finding issuer-paid credit rating agencies such as 
S\&P improve their information quality when an investor-paid agency initiates coverage. Xia argues that because investor-paid agencies earn revenue from a subscription-based fee from investors, the agencies have no incentive to inflate ratings. As a result, the investor-paid firm pressures the issuer-paid one to become more responsive to changing credit risk and incorporate higher information content. Thus, reputational concern for the major credit rating agencies is only relevant when competing against investor-paid agencies rather than when competing against other issuer-paid agencies. Overall, the literature reveals reputational concern is not a large enough factor to positively influence the actions of the credit rating agencies.

Another source of fault the literature explores is the effect the complexity of CDOs has on potential ratings. Since CDOs have complicated correlation factors and future pool default rates, Coval, Jurek, and Stafford (2009) argue that the senior tranches are at risk of inaccurate estimation of correlation and payoffs in various firm and macroeconomic states. Skreta and Veldkamp (2009) theorize that increased complexity of securities also leads to higher variations in ratings. Consistent with rating shopping, greater variation means that unbiased yet more favorable ratings will be chosen by the underwriters. This variation produces the systematic bias in the disclosed ratings even with agencies' estimates of the asset's true quality. Finally, Opp, Opp, and Harris (2013) consider the higher costs of obtaining all necessary information in order to rate more complex securities. In this case, CDOs have inflated tranche ratings due to the unwillingness of rating agencies to spend the necessary resources to fully understand the collateral. Whereas corporate bonds are easily rated due to the agency's experience and 
previous research, complexity of CDOs leads to less due diligence, more estimation, and a greater chance of incorrectly assigning ratings.

The literature contains empirical studies on the effect of rating shopping on CDOs beyond the paper by Griffin and Tang (2013). Sangiorgi and Spatt (2011) find that because selective disclosure inherently creates upward ratings bias, mandatory disclosure of all rating solicitations is necessary for investors to make fully informed decisions. Once investors are informed about the number of ratings solicited and eventually granted, they can more completely understand the collateral of the CDO and develop their own credit assessments. He, Qian, and Strahan (2015) separately test the AAA and sub-AAA tranches of mortgage-backed securities from 2000 to 2006 and find signs of rating shopping in non-AAA rated tranches. The authors conclude rating shopping was present due to the existence of larger losses for single rated tranches compared to multiple rated ones.

Rating catering is prevalent in the literature as well. Bolton, Freixas, and Shapiro (2012) find that competition among credit rating agencies in a duopoly produces less accurate results than having a single, monopoly rating agency, regardless of the complexity of rated security. With a monopoly rating agencies, competitive pressure to maintain market share is nonexistent and the figurative race to the bottom for rating agency standards is avoided. In addition to rating shopping in sub-AAA tranches, He et al. (2015) find rating catering in the AAA tranches. The authors conclude that rating convergence for $97 \%$ of dual-rated tranches means that agencies catered to CDO issuers, 
who would not purchase the ratings unless they received a certain percentage of AAA rated capital.

In this paper, I test two hypotheses based on the findings by Griffin and Tang (2013). The first hypothesis is that credit rating shopping still exists in the post-crisis CDO market. With rating shopping, CDOs with multiple ratings should experience fewer downgrades and better overall performance compared to single rated CDOs. Therefore, additional informational value is contained in multiple ratings and investors will demand a larger credit spread for single rated CDOs. The second hypothesis is that rating catering exists in the market such that dual-rated securities contain no additional informational content and perform similarly to single rated securities. Griffin and Tang (2013) conclude the pre-crisis market for CDOs experienced rating catering because single rated CDOs experienced superior credit performance compared to multiple rated ones. Thus, I contribute to the literature by replicating the study of Griffin in Tang (2013) in the postcrisis period to analyze the impact of the financial crisis and the Dodd-Frank Act on the prevalence of rating shopping and catering.

The rest of this paper is organized as follows. Section 3 describes the data collection process used to replicate Griffin and Tang's study. Section 4 divides the sample into single and multiple ratings to examine the forces of shopping and catering on issuer rating solicitations. Section 5 studies the credit spread difference between single and multiple rated deals to infer investor perception of the additional information of multiple ratings. Section 6 analyzes the downgrades experienced by single and dual-rated 
CDOs to identify potential rating catering. Section 7 concludes and contrasts the findings of the study with those of Griffin and Tang (2013).

\section{Data and Descriptive Statistics}

I first use Bloomberg to examine the $659 \mathrm{CDO}$ deals rated by either Moody's or S\&P and originated from 2009 to 2013 . Bloomberg provides deal and tranche level data for each CDO. Then, I separate the deals into their individually rated tranches, resulting in 3,585 total tranches. Next, I research each individual tranche's credit history on Bloomberg to determine the original and current credit rating. Finally, I isolate the CDO tranches that were originally rated AAA to study their credit spread and downgrade history.

I take a few steps to transform the data I collect from Bloomberg into a sample containing unique, floating rate AAA CDO tranches. First, I eliminate the duplicate CDO deals that have unique ticker symbols. Due to regulation and reporting standards for structured finance products, each CDO does not have a single, exclusive ticker symbol. However, duplicate CDOs normally have an additional letter added to the end of the ticker symbol, making them intentionally easy to recognize. I also check the date of origination and tranche size of the CDO to confirm its duplication.

Next, I eliminate the fixed rate AAA CDO tranches from the Bloomberg data. Most CDOs have floating coupon rates above an index such as 3 month Libor. However, a few deals contain fixed rates. I exclude them from the sample because the difference in credit spreads above the floating, risk free index is a vital variable within the study. 
Finally, I identify the CDO deals in foreign currencies and convert each tranche's original and current outstanding capital into US dollars. This adjustment was necessary for an accurate understanding of the total capital originated during the sample period and the percent capital rated by single and multiple rating agencies.

After making adjustments, the sample contains 458 AAA CDO deals, comprised of 622 AAA tranches. The sample contains some deals with multiple AAA tranches, however the average of 1.36 reveals that the majority of CDO deals only contain a single AAA tranche. Table 1 presents tranche level rating coverage by S\&P, Moody's, and Fitch. Table 2 and Table 3 present deal level regression results for CDO credit spread and downgrade history.

The sample contains AAA tranches with an original balance of $\$ 313$ billion. Overall, roughly $\$ 681$ billion dollars of CDO capital was originated during the period from 2009 to 2013. As a result, $46 \%$ of total capital was assigned a AAA rating, a sizable divergence from the 75-80\% AAA capital level that Griffin and Tang (2013) find in their paper. This decrease in percentage of AAA total capital suggests that rating agencies were assigning smaller portions of low risk tranches to CDOs. Subsequently, rating agencies are also assigning larger portions of higher risk tranches to protect the AAA portion. Since each tranche's rating is dependent on its priority in the payout structure, less capital was being assigned to the senior tranche and more was included in the mezzanine and equity portions as credit enhancements.

Notably, the number of deals and total issued CDO capital in the post-crisis sample is less than the sample size in the study by Griffin and Tang (2013). This relatively smaller sample in the post financial crisis period is the result of increased 
investor caution after frequent defaults and major downgrades of CDOs during the recession. Prior to the financial collapse, investor demand for CDOs was high and the structured product market was experiencing a boom. As a result, Griffin and Tang (2013) examine rating agencies' behavior during the period of rising demand and deal flow. On the other hand, data from 2009 to 2013 provide a smaller sample size because investor demand was much more conservative. As a result, fewer CDO deals were originated. This smaller data sample results in less statistically significant regressions than Griffin and Tang (2013). However, the sample is large enough to draw moderately robust conclusions and is not a major concern.

\section{Does CDO Issuance by Rater Suggest Shopping or Catering?}

Table 1 reports the tranche-level breakdown of CDOs rated by S\&P, Moody's, and Fitch from 2009 to 2013. Only deals from Bloomberg rated AAA by at least S\&P or Moody's are included in Table 1. Panel A sorts the 622 tranches into credit rating agency coverage to contrast the amount of solo and multiple rated capital. Panel B sorts the tranches into the percentage of deals and capital with matching AAA ratings by both S\&P and Moody's to analyze disagreement across ratings. All tranches rated AAA by either S\&P or Moody's at origination are included in Panel B.

Panel A of Table 1 shows that $41 \%$ of AAA CDO capital had a single rating by either S\&P or Moody's. Therefore, 59\% of capital received dual-ratings, with S\&P and Moody's jointly rating $32.4 \%$. An additional .2\% of capital was rated by S\&P, Moody's, and Fitch while Fitch rated $26.5 \%$ in conjunction with either S\&P or Moody's. While 
S\&P and Moody's account for the majority of ratings, the sample is relatively evenly divided between solo and multiple ratings.

The $41 \%$ of solo rated capital in the post-crisis sample is a sharp contrast to the $8.3 \%$ in the pre-crisis period from Griffin and Tang (2013). The dramatic increase in solo ratings and subsequent decrease in multiple ratings can be explained by the change in the regulatory environment after the Dodd-Frank Act. Before the financial crisis, CDO issuers had the incentive to shop their CDO to multiple rating agencies and seek the most favorable rating. Once issuers obtained a favorable AAA rating, they had the incentive to pressure other agencies into catering to match the existing CDO rating. For these reasons, Griffin and Tang (2013) find that $92 \%$ of CDOs had at least two ratings.

There are two possible explanations for the sizable increase in single rated deals after the financial crisis. The first relies on the assumption that Dodd-Frank essentially prohibits rating shopping by requiring disclosure of solicited ratings. In this case, CDO issuers with deals on the margin of deserving two AAA ratings choose not to solicit a second rating for fear the deal will receive mismatched ratings. However, the ability of the Dodd-Frank Act to prohibit rating shopping does not seem likely because it only requires disclosure of formally solicited ratings.

The second, more plausible, explanation suggests that the regulatory changes have merely shifted the process by which CDO issuers conduct rating shopping. Since they must disclose all formally solicited ratings, CDO issuers appear to be shopping by assessing rating agency perception of the CDO in preliminary discussions. Since issuers cannot pay the contract breaking fee to hide the rating, rating agencies have more independence and are less susceptible to competitive pressure from other rating agencies. 
Thus, unless credit assessments during preliminary discussion are positive, CDO underwriters do not solicit a rating for fear of receiving two different ratings. This leads to $\mathrm{CDO}$ issuers soliciting multiple ratings only when they are confident the collateral can receive matching AAA ratings. On the other hand, solo rated capital suggests that the underwriters shopped the most favorable agency in preliminary talks and considered the deal fortunate to even receive a single AAA rating.

Thus, I suspect rating shopping is still prevalent despite Dodd-Frank due to the shift toward informal, preliminary talks with rating agencies. Even though shopping still seems to be prevalent pre-crisis, rating agencies do not appear to be catering and adding dual certification to all deals. As a result, many deals that would have received an additional, catered rating pre-crisis are now only seeking a single AAA rating. This means multiple rated deals now have additional information for investors compared to single rated ones. Since agencies do not seem to be inevitably matching dual certifications, the amount of capital with a single rating is significantly greater than Griffin and Tang (2013).

Only .2\% of the capital in the sample received ratings from S\&P, Moody's, and Fitch. This is another sizable difference from Griffin and Tang's sample which contained $37.2 \%$. I suspect that not only are issuers now hesitant to shop their CDOs to get three ratings, but investors value the significant additional informational signal of multiple ratings much less than before the financial crisis. For example, if investors still believed multiple ratings added additional information, high quality CDOs would solicit three ratings, investor demand for them would be high, and investors would be willing to pay a premium. However, in the post-crisis period from 2009-2013, only 4 tranches existed 
with ratings from all three major credit rating agencies. The absence of more deals suggests that demand for products with three ratings is rarely worth the risk of receiving an unfavorable rating.

The absence of CDOs with three ratings can also be considered as a general reduction in investor confidence in the rating agencies themselves. S\&P, Moody's, and Fitch took a large portion of the blame for the financial crisis due to their inaccuracy and systematic bias of structured financial products. Griffin and Tang (2013) show that CDOs rated by multiple rating agencies were downgraded more severely than solo rated CDOs. Meanwhile, dual-rated CDOs had tighter credit spreads. As a result, pre-crisis investors were unaware they were receiving less compensation for holding riskier securities. Now, as Dodd-Frank encouraged, investors may be performing more independent analysis of CDOs and valuing additional ratings less.

The $.2 \%$ of deals rated by S\&P, Moody's, and Fitch also suggests that investors have considered the failure of credit rating agencies during the financial crisis and do not have confidence they will change their rating behavior in the future. Rating agencies' reputations were tarnished after the financial crisis and investors do not seem willing to trust the agencies to disagree with each other. Thus, because investors do not seem to trust the agencies to disagree with each other, $\mathrm{CDO}$ issuers are not soliciting all three rating agencies because there is no demand for the added informational content.

Panel B of Table 1 shows that $98.7 \%$ of tranches originated during the period received matching initial AAA ratings. S\&P assigned a AAA rating to only 1 deal which Moody's rated lower while Moody's rated 4 deals AAA which S\&P assigned a more 
unfavorable rating. Overall, the $1.3 \%$ of mismatched AAA deals reveals that disclosed disagreement in initial ratings for AAA CDOs issued into the market was essentially nonexistent during the period.

Griffin and Tang (2013) find that 5.3\% of the deals originated in the pre-crisis period received a AAA rating from one agency but was rated lower by the other. Thus, due to rating shopping, the vast majority of CDOs issued before the financial crisis had matching ratings. If a $\mathrm{CDO}$ did not receive favorable, matching ratings from both $\mathrm{S} \& \mathrm{P}$ and Moody's, the underwriter could hide the unfavorable one and report the CDO as solo rated AAA.

Before the financial crisis, the $5.3 \%$ of deals rated AAA by one agency but not the other suggest that the CDOs were initially not rated AAA by a rating agency but still issued by the underwriter regardless. Then, after issuance, the CDO obtained an additional AAA rating. However, due to high demand for CDOs before the financial crisis, the $\mathrm{CDO}$ issuers were relying on the assumption that demand for the sub-AAA CDO would still be high enough to sell the CDO at a sufficient price. Investor demand for sub-AAA quality capital brought the sub-AAA CDO to market even with a disclosed, unfavorable rating in $5.3 \%$ of cases.

As a result of the informal rating shopping process that I suspect is occurring in response to Dodd-Frank, only $1.3 \%$ of the sample contains mismatched AAA ratings. The $1.3 \%$ of differing AAA tranches also suggests that investor tolerance for risky structured products such as subordinate tranches of CDOs decreased after the financial crisis. The investor perception of CDOs shifted very negatively after most junk-grade 
structured products defaulted during the financial crisis. As a result, CDO underwriters that solicited multiple ratings and received mismatched results did not choose to issue the product. Because these CDOs were scrapped and not sold to the market, they are not present in the data.

The data suggest that mismatched ratings after Dodd-Frank became a figurative death penalty for a CDO issuance. Instead of leading to more disagreement in originated CDO tranches, the Dodd-Frank Act led to mismatched CDOs not being issued in the market. This makes it appear as though the credit rating agencies have increased dependence in ratings because mismatched CDOs are not present in the data. However, in reality, CDO underwriters appear to have cancelled the deals and re-bundled the collateral into a new deal (CreditFlux, 2016).

\section{Do Investors Perceive Additional Information from Multiple Ratings?}

Investor perception of risk is intrinsically priced into in the yield spread at issuance of each tranche of a CDO. Since CDOs are floating rate credit instruments, they pay a spread over an interest rate index, typically 3-month Libor. In the case of rating shopping, investors are willing to accept tighter spreads for the informational value of multiple ratings because single rated CDOs are interpreted as unsuccessfully shopped. Since ratings are still unbiased assessments of quality, two AAA ratings is a signal of superior underlying collateral compared to only one rating. Thus, single rated CDOs are considered riskier investments and have a higher credit spread. On the other hand, in the case of rating catering, multiple ratings have no added informational value since the second ratings is biased upward. Since single rated CDOs could have also received a 
second, catered rating, there is no added information and the yield spreads should be equivalent.

I analyze how investors interpret multiple ratings by examining the weighted average yield spread of a CDO deal's AAA rated tranches. To examine the effect of multiple ratings on credit spreads, I separate the data into three mutually exclusive, binary groups according to whether the CDO was rated by S\&P, Moody's, or both. Thus, the One Rater variable is classified as a CDO with AAA capital only rated by either S\&P or Moody's, but not both. Next, the Two-Disagree variable represents CDOs rated by both S\&P and Moody's that received more AAA tranches from one agency that the other. Finally, Two-Agree is the default category that represents CDOs that received a matching number of AAA tranches from both S\&P and Moody's. I include binary control variables for whether Fitch also rated the CDO deal, whether the collateral is a synthetic CDO, and the year of issuance. In the regression, the base case scenario is a CLO deal rated AAA by both agencies in 2013 .

Table 2 shows the ordinary least squares regression results of AAA spreads for CDOs rated by either S\&P or Moody's, strictly S\&P, and strictly Moody's. When all CDOs are used in the regression, investors demand an additional spread of 4.1 basis points for deals only rated by one agency. The spread increases to roughly 10 basis points for deals exclusively rated by S\&P. This increase in credit spread is consistent with the findings of Griffin and Tang (2013) and suggests that investors still view CDOs that only received one rating as riskier.

The sample only contains 4 deals classified as Two-Disagree from 2009 to 2013. A decrease in credit spreads by roughly 50 basis points from the case where the rating 
agencies agree on rating is not an intuitive result. Due to the very small sample size, the regression is possibly not fully controlling for the noise in the data. Deals where the two rating agencies do not agree on AAA capital may be fundamentally different in underlying collateral quality, tranche structure, or other factors not accounted for in the regression. Because of the small sample, the regression would need more data to produce a robust result.

Deals that include a Fitch rating are priced at 14.6 basis points less than deals without one. Even with the relatively small sample size of 459 deals, the Fitch rating is statistically significant at the $10 \%$ level. The tighter credit spread investors are willing to accept suggests that Fitch adds additional informational value as a second rater. This result is also consistent with the finds of Griffin and Tang (2013).

Overall, the results of the OLS regression imply that investor perception about the presence of multiple raters in the credit spreads of deals has not changed after the crisis. Since the demand for dual-rated CDOs has driven the credit spread below single rated ones, investors are exhibiting the belief that there is some additional informational value in multiple ratings. As a result, the higher credit spreads for single rated CDOs suggest that investors do not seem to think rating catering is a dominant factor within the CDO market. Unlike before the financial crisis, multiple ratings contain useful information for investors to price spreads, rather than merely adding an additional rating that replicates the original one. Thus, even though Griffin and Tang (2013) find this belief incorrect before the crisis, the data suggest it is accurate post-crisis.

\section{Does CDO Performance Suggest Shopping or Catering?}


I examine credit downgrades of CDOs from 2009 to 2013 to analyze the prevalence of rating shopping or catering in the post-crisis market. A CDO's credit rating is meant to be a forward-looking assessment that represents the future downgrade and default risk of the security. As a result, credit ratings reflect the securities' expected performance in a variety of potential macroeconomic environments.

I graphically represent the average downgrades of solo and multiple rated CDOs each year. First, I sort each CDO deal into the mutually exclusive categories of One Rater or Two-Agree. The criteria for these categories are identical to the categories presented previously in Table 2. I exclude the Two-Disagree category because only 4 deals exist within the sample and may not be representative. Then, I divide the CDOs into year of issuance and compare the average of exclusively S\&P or exclusively Moody's rated downgrades with multiple rated downgrades each year.

The majority of credit downgrades occur between 2009 and 2011. One possible reason that rating downgrades are concentrated in the older CDOs is that they have had more time to be downgraded. Because the securities originated in 2012 and 2013 have only existed for about 3 years, not enough changes have occurred to justify a downgrade. The other theory why the CDOs from 2009 to 2011 experienced the vast majority of downgrades is that they were originated during the later stages of the recession. Because the recession was still affecting the economy, payers of the underlying collateral of CDOs such as loans and mortgages were still delinquent or defaulting on their payments. By 2012 and 2013, the economy had improved to the point where the underlying payers of CDO collateral had recovered and were consistently paying their obligations. 
Figure 1 graphically shows the average number of notches that the lowest AAA tranche of CDOs rated by S\&P was downgraded by February, 2016. By comparing average downgrades on a yearly basis, Figure 1 suggests there is not a consistent difference in the rating downgrade history between exclusively $\mathrm{S} \& \mathrm{P}$ rated and dual-rated CDOs. This result differs from the findings of Griffin and Tang (2013), where S\&P single rated CDOs consistently experienced fewer downgrades than CDOs with matching AAA ratings.

Similarly, Figure 2 depicts the average number of notches the lowest AAA tranche of CDOs rated by Moody's was downgraded by February, 2016. However, Figure 2 suggests that Moody's AAA rated CDOs were consistently experiencing more downgrades than deals with dual AAA ratings. CDOs rated exclusively by Moody's appear to perform much worse than dual-rated deals, with an average downgrade over 2 notches greater. Over the same time span, $\mathrm{S} \& \mathrm{P}$ rated $\mathrm{CDOs}$ experienced an average downgrade of .5 notches while Moody's experienced almost 2.5 notch downgrades. Again, this result differs from Griffin and Tang's study that found Moody's rated CDOs performed better in 2006 and 2007 compared to dual-rated CDOs.

To empirically analyze whether rating performance suggests rating shopping or catering during the post-crisis era, I examine the likelihood of downgrade for single and multiple rated CDOs. Table 3 is an ordered logit regression reporting the odd ratios as the coefficient for each variable. As a result, coefficients represent the likelihood of rating downgrade relative to CDOs with matching AAA ratings from S\&P and Moody's.

The data is again sorted into the mutually exclusive variables One Rater, TwoDisagree, and Two-Agree according to the previously mentioned criteria. The Credit 
Spread variable represents the weighted average credit spread of all AAA tranches of the CDO deal scaled by 10 basis points. Fitch Rated is a dummy variable to account for whether Fitch also rated the deal. The $C D O$ variable is a dummy variable accounting for whether the deal is a synthetic CDO. Finally, the regression controls for the year of issuance of the CDO in an attempt to minimize omitted risk.

Table 3 shows that a AAA deal exclusively rated by $\mathrm{S} \& \mathrm{P}$ is 1.8 times more likely to be downgraded than a deal rated AAA by both S\&P and Moody's. Furthermore, Table 3 shows that a AAA deal rated only by Moody's is roughly 3.9 times more likely to experience downgrades compared to a deal rated AAA by both agencies. Griffin and Tang (2013) find that the relative likelihood of downgrades was roughly half as likely for single rated CDOs compared to dual ratings before the financial crisis. Thus, the results in Table 3 differ from the evidence of rating catering Griffin and Tang (2013) discover in their study.

As a result, the findings in Table 3 suggest that there is valid informational content in dual ratings because the capital rated by both S\&P and Moody's is less likely to experience rating downgrades than capital rated exclusively by either agency. In the post-crisis period, the result could be explained by the disappearance of rating agency catering. Rating agencies do not seem to be willing to simply match AAA ratings from other agencies in order to compete for revenue. Without rating catering, the single rated CDOs appear to be unsuccessfully shopped. This means that only one agency is willing to give a AAA rating, suggesting inferior collateral compared to multiple rated deals. On the other hand, CDO underwriters seeking multiple ratings are confident in receiving uniform AAA ratings. As a result, CDOs with a single rating occur when CDO issuers 
only have enough confidence to approach one rating agency due to worse underlying collateral. Accordingly, this collateral is riskier than the collateral of multiple rated CDOs at issuance and experiences more frequent ratings downgrades.

Most importantly, Table 3 suggests that the presence of rating catering found by Griffin and Tang (2013) is not a factor in the time span from 2009-2013. With rating catering, CDOs with single ratings experience fewer downgrades than multiple rated CDOs because the capital was not initially inflated to match the other rating agency in an attempt to gain more revenue and market share. Before the financial crisis, the combination of rating shopping and catering resulted in large, upward biases in CDO ratings due to competitive pressure. In the post crisis market, $\mathrm{CDO}$ issuers continue to rating shop by assessing rating agency favorability in preliminary conversations. However, since catering do not seems to be prevalent though, additional ratings are a signal of superior collateral. The lack of rating catering suggests that credit rating agency behavior, possibly in response to Dodd-Frank's efforts to re-establish rating independence, has changed since the financial crisis. Dually rated CDOs are now experiencing less credit downgrades due to better underlying collateral and are hypothetically less risky than single rated ones.

\section{Conclusion}

Overall, I find that there has been a vast increase in the amount of single rated CDOs issued into the market after the financial crisis (Table 1). Investor perceived dualrated CDOs as less risky than deals rated exclusively by either Moody’s or S\&P (Table 2). Furthermore, the superior credit performance of dual-rated CDOs suggests investors 
correctly perceived the added risk of single rated CDOs and correctly valued the additional informational content of dual-rated deals (Table 3). These results differ from the findings before the financial crisis by Griffin and Tang (2013) that investors perceived dual-rated deals to be safer yet the deals suffered worse credit performance compared to single rated CDOs. Previously, investors seemed to be unware of or incorrectly assuming rating catering was not a prevalent force in the market. However, in the post-crisis market, I find investors are correctly pricing dual-rated CDOs with the assumption that rating catering has been addressed and disappeared.

I also find evidence in Table 1 that rating shopping is still active in the post-crisis CDO market. The results suggest that the elimination of the contract-breaking fee has changed rating shopping into informal, preliminary conversations with rating agencies. The increase in single rated deals and subsequent plummet of triple rated deals implies underwriters are much more careful about rating agency's preliminary assessments. As a result, CDOs with superior credit quality obtain multiple ratings due to successful preliminary talks and underwriter confidence. Lower credit quality deals are shopped to the most favorable preliminary conversation and underwriters are content to receive a single AAA rating. With competitive pressure affecting S\&P and Moody's ratings less, the required disclosure of formally solicited ratings appears to have merely change the process of rating shopping. 


\section{References}

Ashcraft, A., P. Goldsmith-Pinkham, and J. Vickery. 2010. MBS Ratings and the Mortgage Credit Boom. Federal Reserve Bank of New York, Staff Report 449.

Bolton, P., X. Freixas, and J. D. Shapiro. 2012. The Credit Ratings Game. Journal of Finance 67, 85-112.

Coval, J. D., J. W. Jurek, and E. Stafford. 2009. Economic Catastrophe Bonds. American Economic Review 99, 628-666.

CreditFlux. 2016. Repricing of Risk Sees 12 Loan Deals Scrapped in Q4, says Fitch. <http://creditflux.com/Investing/2016-01-28/Repricing-of-risk-sees-12-loandeals-scrapped-in-Q4-says-Fitch>

Golan, L., C. Parlour, and U. Rajan. 2011. Competition, Quality, and Managerial Slack. Working Paper, University of Michigan

Griffin, J. M., and D. Y. Tang. 2011. Did Credit Rating Agencies Make Unbiased Assumptions on CDOs? American Economic Review: Papers \& Proceedings 101, 125-130.

Griffin, J. M., and D. Y. Tang. 2012. Did Subjectivity Play a Role in CDO Credit Ratings? Journal of Finance 67, 1293-1328.

Griffin, J. M., J. Nickerson., and D.Y. Tang, 2013. Rating Shopping or Catering? An Examination of the Response to Competitive Pressure for CDO Ratings. Review of Financial Studies 26 (9), 2270-2310. 
He, J., J. Qian, and P. Strahan. 2011. Credit Ratings and the Evolution of the MortgageBacked Securities Market. American Economic Review Papers and Proceedings $101,131-135$.

He, J., J. Qian, P. Strahan. 2015. Does the Market Understand Rating Shopping? Predicting MBS Losses with Initial Yields. Review of Financial Studies 29 (2), 457-485.

Opp, C., M. Opp, and M. Harris. 2013. Rating Agencies in The Face of Regulation. Journal of Financial Economics 108, 46-61.

Sangiorgi, F., and C. Spatt. 2011. Opacity, Credit Rating Shopping, and Bias. Working Paper, Carnegie Mellon University.

Skreta, V., and L. Veldkamp. 2009. Rating Shopping and Asset Complexity: A Theory of Rating Inflation. Journal of Monetary Economics 56, 678-695.

U.S. Securities and Exchange Commission. 2014. Dodd-Frank Spotlight: Credit Rating Agencies. <http://www.sec.gov/spotlight/dodd-frank/creditratingagencies.shtml>

Xia, H. 2013. Can Investor-Paid Credit Rating Agencies Improve the Information Quality of Issuer-Paid Rating Agencies? Journal of Financial Economics, Forthcoming. 


\section{Appendix}

Table 1

Amount of total Bloomberg CDOs rated by rating agencies

Panel A: AAA tranche-level rating coverage

\begin{tabular}{lrrrr}
\hline & Number & \% Total & Capital (\$B) & \% Capital \\
\hline Solo Rating & 137 & $22.0 \%$ & 128.1 & $41.0 \%$ \\
S\&P & 49 & $7.9 \%$ & 21.8 & $7.0 \%$ \\
Moody's & 88 & $14.1 \%$ & 106.3 & $34.0 \%$ \\
Multiple Ratings & 485 & $78.0 \%$ & 184.6 & $59.0 \%$ \\
SP \& Moody's & 379 & $60.9 \%$ & 101.3 & $32.4 \%$ \\
SP \& Fitch & 57 & $9.2 \%$ & 15.6 & $5.0 \%$ \\
Moody's \& Fitch & 45 & $7.2 \%$ & 67.1 & $21.5 \%$ \\
S\&P, Moody's, and Fitch & 4 & $0.6 \%$ & 0.5 & $0.2 \%$ \\
\hline Total & 622 & - & 312.7 & -
\end{tabular}

Panel B: Degree of AAA tranche ratings agreement

\begin{tabular}{lrrrr}
\hline & Number & \% total & Capital (\$B) & $\%$ Capital \\
\hline Same rating & 383 & $98.7 \%$ & 101.9 & $96.8 \%$ \\
S\&P AAA only & 1 & $0.3 \%$ & 0.0 & $0.0 \%$ \\
Moody's AAA only & 4 & $1.0 \%$ & 3.3 & $3.2 \%$ \\
\hline
\end{tabular}


Table 2

Multiple credit ratings and credit spreads

\begin{tabular}{lccc}
\multicolumn{4}{c}{ All CDOs } \\
\hline \multirow{4}{*}{ Ene rater } & 4.151 & 10.23 & -2.910 \\
& $(6.357)$ & $(6.310)$ & $(7.574)$ \\
Two - disagree & $-47.36^{*}$ & $-55.26 * * *$ & $-43.83 *$ \\
& $(24.81)$ & $(19.35)$ & $(23.55)$ \\
Fitch rated & $-14.63 *$ & -11.41 & -12.10 \\
& $(7.606)$ & $(7.954)$ & $(9.754)$ \\
CDO & 13.20 & $-100.2 * * *$ & $114.3 * * *$ \\
& $(24.39)$ & $(25.87)$ & $(32.71)$ \\
2012 & $12.85 * *$ & $9.442 * *$ & $14.65 * *$ \\
\multirow{4}{*}{ 2011 } & $(5.629)$ & $(4.338)$ & $(5.784)$ \\
& $-23.61 * * *$ & 1.043 & $-17.83 * *$ \\
2010 & $(7.224)$ & $(6.309)$ & $(7.388)$ \\
& $-23.56 * * *$ & $-18.56 * *$ & $-17.90 *$ \\
2009 & $(8.770)$ & $(7.866)$ & $(9.496)$ \\
& $-33.65 * * *$ & $-18.75 *$ & $-36.86 * * *$ \\
Intercept & $(8.497)$ & $(10.11)$ & $(9.327)$ \\
& $132.9 * * *$ & $130.5 * * *$ & $131.3 * * *$ \\
Observations & $(3.721)$ & $(2.843)$ & $(3.644)$ \\
& 460 & 366 & 387 \\
& 0.118 & 0.125 & 0.182 \\
\hline
\end{tabular}

Standard errors in parentheses $* * * \mathrm{p}<0.01, * * \mathrm{p}<0.05, * \mathrm{p}<0.1$ 
Figure 1

S\&P downgrades

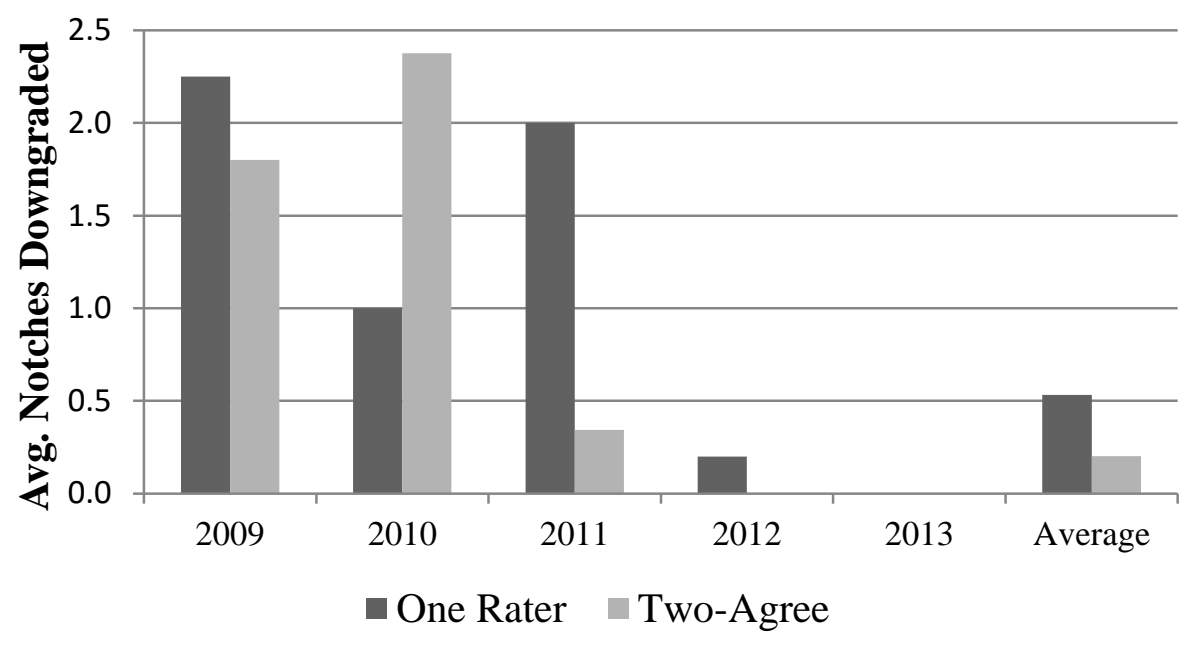


Figure 2

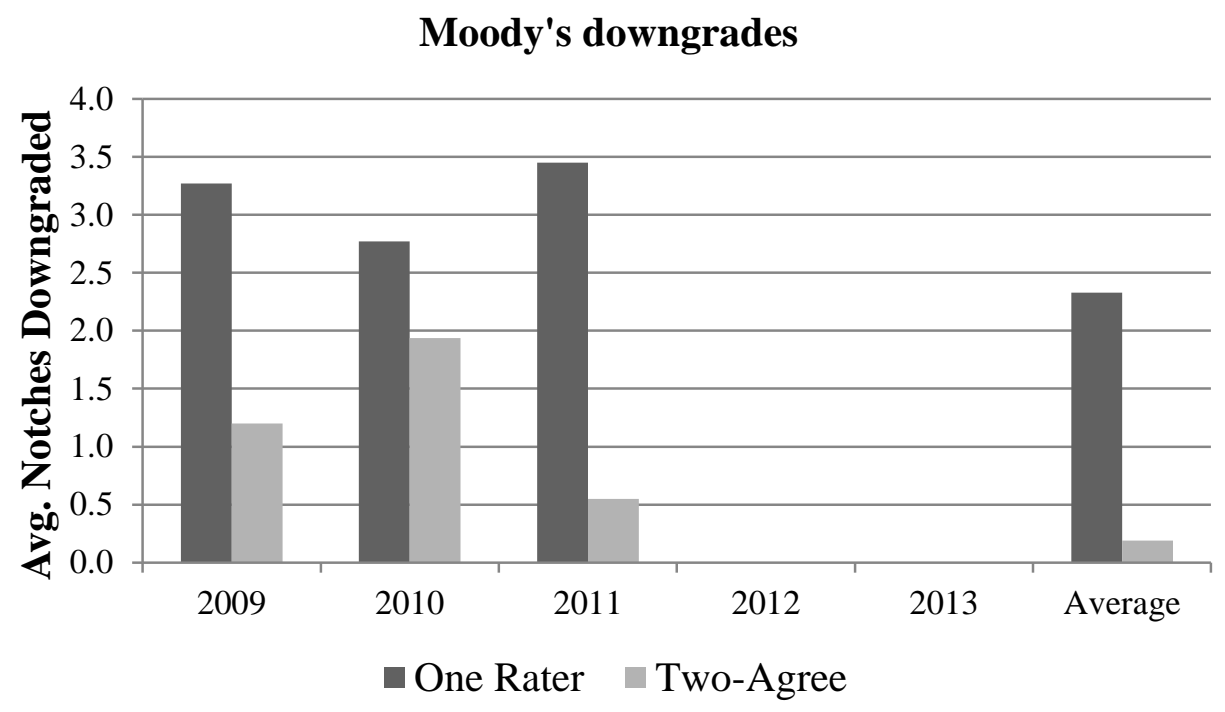


Table 3

Multiple credit ratings and downgrades

\begin{tabular}{lcc}
\multicolumn{3}{c}{ All CDOs } \\
\hline & S\&P downgrades & Moody's downgrades \\
\hline One rater & 1.807 & $3.888 * * *$ \\
& $(0.94)$ & $(2.78)$ \\
Two - disagree & 1.486 & 13.289 \\
& $(.35)$ & $(2.32)$ \\
Credit spread & $0.862 * * *$ & 0.836 \\
& $(-3.08)$ & $(-4.50)$ \\
Fitch rated & 0.411 & 0.6 \\
& $(-.99)$ & $(-1.02)$ \\
CDO & 0.568 & 2.35 \\
& $(-.35)$ & $(0.00)$ \\
Year controls & Yes & Yes \\
Observations & 363 & 385 \\
R-squared & 0.371 & 0.402 \\
\hline \multicolumn{3}{c}{ Z-scores in parentheses } \\
& $* * * \mathrm{p}<0.01, * * \mathrm{p}<0.05, * \mathrm{p}<0.1$
\end{tabular}

